\title{
EFEKTIVITAS PENERAPAN PENDAFTARAN HAK TANGGUNGAN MELALUI SARANA ELEKTRONIK PADA PT. BPR PEDUNGAN DENPASAR
}

\author{
Nyoman Mahayu, Sagung Laksmi Dewi, Ni Made Puspasutari Jianti \\ Fakultas Hukum Universitas Warmadewa Denpasar, Bali- Indonesia \\ lifeofmay@gmail.com, laksmidewi29@gmail.com, puspasutariujianti@gmail.com
}

\begin{abstract}
Abstrak
Aktivitas peminjaman uang yang seringkali terkait oleh syarat menyerahkan jaminan hutang banyaknya dilaksanakan secara individual mau pun badan usaha. Pada kenyataannya dalam melaksanakan perjanjian kredit seringnya didapati debitur yang melakukan pengajuan kredit berupa jaminan tanah untu k mendapatkan kredit dengan nominal tertentu. Pihak bank akan lebih berani memberikan kredit tanah yang memiliki ekonomis yang tinggi dan nilai tanah selalu meningkat dari waktu ke waktu dan dibuat kan Hak Tanggungan, yaitu Hak jaminan yang dibebankan pada hak atas tanah. Tujuan dari penelitian ini adalah untuk mengetahui mekanisme pendaftaran hak tanggungan melalui sarana elektronik pada PT.BPR Pedungan Denpasar, serta mengetahui kendala-kendala yang dihadapi dalam penetapan pendaftaran hak tanggungan melalui sarana elektronik pada PT. BPR Pedungan Denpasar. Jenis penelitian ini adalah bagian dari penelitian hukum sosiologis yang meliputi pengidentifikasian hukum yang bersifat tidak tertulis serta meneliti efektivitas huku m. Dalam analisis terhadap teoritis hukum melalui pandangan ilmu hukum mulai dari secara normatif maupun empiris. Teknik pengumpulan data primer dalam penelitian ini adalah metode wawancara.
\end{abstract}

Kata Kunci: Hak Tanggungan, Kredit, Sarana Elektronik.

\begin{abstract}
The activity of borrowing money, which is often related to the condition of submitting debt guarantees, is mostly carried out individually or by business entities. In fact, in carrying out credit agreements, it is often found that debtors apply for credit in the form of land guarantees to get credit with a certain nominal value. The bank will be more daring to provide land loans that have a high economy and the value of the land always increases from time to time and Mortgage Rights are created, namely collateral rights imposed on land rights. The purpose of this study was to determine the mechanism for registering mortgage rights through electronic means at PT.BPR Pedungan Denpasar, and to find out the obstacles faced in determining mortgage registration through electronic means at PT.BPR Pedungan Denpasar. This type of research is part of sociological legal research which includes identifying unwritten laws and examining the effectiveness of laws. In the analysis of legal theory through the view of legal science, starting from normative and empirical. The primary data collection technique in this research is the interview method.
\end{abstract}

Keywords: Mortgage, Credit, Electronic Facilities.

\section{PENDAHULUAN}

Seizing dengan kemajuan teknologi, kebutuhan manusia juga ikut berkembang. Perihal tersebut memberikan akibat peningkatan aktivitas pembangunan, menuiut meningkatnya kebutuhan terhadap ketersediaan pembiayaan yang mayoritas didapatkan lewat airtivitas kredit dimana setiap usaha memerl ukan modal yang tidak sedikit. Sehingga memerlukan pinjaman untuk memenuhi kebutuhan tersebut. (Sumardjono Maria, 2004)

Teknologi jaringan komputer semakin berkembang pesat ditandai dengan adanya LAN (Local Area Network) yaitu jaringan pada area lokal serta jaringankomputer yang lebih besar disebut WAN (Wide Area Network) (Anggara, 2010). Peningkatan kualitas layanan publik menjadi satu hal penting untuk memperbaiki tingkat kepercayaan masyarakat kepada pemerintah (Hardiyansyah, 2011). Masyarakat setiap waktu selalu menuntut layanan publik yang berkualitas dari pemerintah (Sinambela, 2011).

Suatu contoh yang bisa dipergunakan dalam pemenuhannya yaitu lewat kredit yang dapat diajukan kepada lembaga keuangan seperti pihak bank. Aktivitas peminjaman uang yang terkait oleh 
berbagai syarat-syarat untuk menyerahkan jaminan hutang banyaknya dilaksanakan secara individual maupun dari instansi bisnis. Instansi bisnis yang secara umum menegaskan dalam syarat-syarat bagi orang yang meminjam agar melakukan penyerahan sebuah objek penjamin hutang dalam peininjaman yang dilakukan (Bahsan,2017).

Pada realitas pelaksanaan perjanjian kredit seringkali didapati bahwa debitur yang melakukan pengajuan kredit disertai penjamin berupa tanah untuk mendapatkan kredit dengan nominal tertentu . Pihak bank akan lebih berani memberikan kredit dikarenakan tanah bemilai ekonomi secara tinggi serta nilai tanah senantiasa mengalami peningkatan seiring berjalannya waktu. Jaminan tanah ini selanjutnya akan dibuatkan hak tanggungan. Keterlibatan PPAT/N otaris dan Kantor Pertanahan dalam hal ini sangat diperlukan demi mendapatkan kepastian huku m mau pun dilindungi berbagai pihak yang melaksanakan perjanjian kredit, yakni kreditur dan debitur dan/atau pemilik jaminan.

Dengan berjalannya waktu, untuk memudahkan akses mempersingkat waktu diciptakanlah terobosan baru beru pa pelayanan secara online. Berbagai macam keperluan manusia dapat dilaku kan secara elektronik dan online seperti transaksi perdagangan secara online, transaksi jasa secara online, bahkan pelayanan umum pada sistem pemerintah turut banyaknya mempergunakan sistem digital yang dilaksanakan secara online. Begitu pula dengan pelayanan dibidang pertanahan, layman elektronik ini bertujuan memberikan kemudahan masyarakat terutama masyarakat yang ingin mengajukan pendaftaran administrasi yang berhu bungan dengan pertanahan.

Berlakunya ketentuan mengenai pendaftaran hak tanggungan secara elektroni k dalam waktu yang terbilang sangat tingkat ini tentunya juga memberikan kendala dan permasalahan dalam penerapannya. Pihak bank selaku kreditur dalam sistem pendaftaran HT elektronik juga turut berperan dalam penginputan data selain juga dilakukan oleh PPAT. Sistem Elektronik Hak Tanggungan Terintegrasi (HT-el) merupakan suatu sistem elektronik yang diintegrasikan dengan pengembangan dari unit teknis yang bertugas pada bagian data maupun informasi dalam pemrosesan layman hak tanggungan secara elektronik. Pada sistem tersebut sebagai suat $u$ bagian pelayanan yang tersedia pada Kantor Pertanahan dalam masa sekarang yang menjadi bentuk pembatasan untuk berinteraksi secara fisik. Hal tersebut adalah Upaya mewujudkan nilai Kementerian ATR/BPN yakni terpercaya, melayani serta profesional.

Terdapat berbagai macam kendala yang dihadapi dalam penerapan HT secara elektronik. Salah satunya yang hendak dikaji dalam penelitian skripsi ini yaitu kendala yang dihadapi oleh PT. Bank Perkreditan Rak yat Pedungan (selanjutnya disebut BPR Pedungan) dalam penerapan pendaftaran HT elektronik melalui system online.

Tanda tangan elektronik adalah sebagai alat autentikasi dokumen, yaitu dokumen digital tersebut memang dikeluarkan melalui sistem elektronik oleh KementerianATR/BPN dan tidak terdapat perubahan sejak dokumen tersebut ditandatangani secara elektronik. Penerapan Tanda Tangan Elektronik dimaksudkan melindungi data dan informasi dari resiko pencurian, pemalsuan, modifikasi serta penyangkalan data (Gunarta et al., 2020). Perkembangan pesat intemet juga menimbulkan berbagai sengketa dan konflik hukum yang cukup serius bagi para pemakainya yakni dengan banyaknya persoalan yang tidak terduga temyata bermunculan beberapa tahun terakhir ini. Hal ini dikarenakan akibat dari pesatnya akselerasi dalam bidang teknologi Informatika (Nurwulan, 2021). Mekanisme pendaftaran Hak Tanggungan Elektronik secara elektronik merupakan layanan terobosan yang berbasis digital atau elektronik yang diluncurkan oleh Kementerian Agraria dan Tata Ruang/Badan Pertanahan Nasional untuk memudahkan pengurusan pertanahan berdasarkan asas keterbukaan, ketepatan waktu, kecepatan, kemudahan dan keterjangkauan dalam rangka pelayanan public (Guntoro et al., 2020).

Berdasarkan latar belakang permasalahan diatas maka penulis merumnuskan tujuan dari penelitian ini adalaha untuk mengetahui mekanisme pendaftaran hak tanggungan melalui sarana elektronik pada PT.BPR Pedungan Denpasar, serta mengetahui kendala-kendala yang dihadapi dalam penetapan pendaftaran hak tanggungan melalui sarana elektronik pada PT. BPR Pedungan Denpasar.

\section{METODE PENELITIAN}

Penggunaan metode penelitian pada penelitian berikut yakni metode penelitian yang berjenis hukum empiris. Jenis penelitian ini adalah bagian dari penelitian hukum sosiologis yang meliputi pengidentifikasian hukum yang bersifat tidak tertulis serta meneliti efektivitas huku m. Dalam analisis terhadap teoritis hukum melalui pandangan ilmu hu kum mulai dari secara normatif mau pun empiris 
bisa meluaskan penget ahuan pada bermacam-macam perspektif yang dipaparkan oleh ilmu wan hukum, mempelajari lebih dalam mengenai hukum yang menjadi bagian dari disiplin ilmu keil miahan (At madja et al., 2018).

\section{PEMBAHASAN}

\section{Pengertian Hak Tanggungan}

Beban hak atas tanah yang menjadi penjamin utang sebelu $\mathrm{m}$ terdapat instansi hak penanggungan dengan demikian digunakan instansi penjamin hipotik. Akan tetapi setelah diberlakukan INUHT, beban hak atas tanah yang menjadi penjamin utang tidak mempergunakan penjamin hipotik lagi, namun memper gunakan penjamin hak tanggungan (Rachmadi Osman, 2011)

Hak tanggungan adalah beban hak terhadap jaminan yang beru pa tanah. Hak tanggungan yang memiliki objek beru pa tanah bisa juga terdiri dari berbagai barang-barang lainn ya yang adalah bagian dari tanah tersebut. Perihal ini dapat memungkinkan dikarenakan sifat fisik yang dimiliki adalah bagian dari tanah tersebut mu lai dari yang telah tersedia atau pun akan tersedia, dapat berbentu k gedung, tumbu han mau pun karya yang dihasilkan.

Hak tanggungan merupakan suatu hak penjamin terhadap tanah pada Hukum Tanah sebagai penguasaan terhadap tanah yang memberikan wewenang bagi suatu kreditur dalam melakukan penjualan mau pun pelelangan pada bagian tanah yang menjadi penjamin untuk melunaskan suatu hutang pada debitur yang yang telah mencederai perjanjian serta melunasinya melalui hasil jual disertai Hak Mendahulu dibandingkan kreditur lainnya (Urip Santoso, 2005).

Mekanisme Pendaftaran Hak Tanggungan pada sistem elektronik tetap harus dicatatkan dalam buku tanah. Ini dilakukan oleh kreditor sampai dengan mencetak Sertifikat Hak Tanggungannya dan melekatkannya pada Sertipikat Hak Atas Tanah (Imanda, 2020). Berkenaan dengan praktik pemberian kredit dengan jaminan hak atas tanah, diperlukan lembaga hak jaminan yang mampu memberikan kepastian hukum bagi pihak-pihak yang berkepentingan dalam mewujudkan masyarakat yang sejahtera, adil dan makmur sesuai dengan Pancasila dan Undangundang Dasar Negara Republik Indonesia Tahun 1945. Undang-undang Nomor 4 Tahun 1996 tentang Hak Tanggungan Atas Tanah Beserta Benda-benda Yang Berkaitan Dengan Tanah tersebut atau disingkat "UUHT" kemudian dibentuk untuk memenuhi kebutuhan masyarakat mengenai hal itu (Eugenia Liliawati, 1996).

Hak tanggungan adalah suatu aktiv'itas mendaftarkan tanah. W alaupun begit $\mathrm{u}$ hak tanggungan pada hu kum tanah tidak memiliki arti jika secara hakikat $n$ ya mau pun sifat-sifat dari kelembagaan hukum wajib dilakukan penerapan di dalamnya. Sebagai contoh sifat tunai kelembagaan menjual dan membeli tanah. Hak tanggungan tidak sebagai bagian dari dengan demikian tidak diwajibkan untu k mematuhi peraturan hukum yang diberlaku kan bagi kelembagaan adat.

Proses pendaftaran hak tanggungan yang dalam UU Hak Tanggungan dilakukan dengan jalan didaftarkan secara manual pada Kantor Pertanahan tempat objek hak tanggungan berada saat ini telah dilakukan pembaharuan peraturan tentang pendaftaran hak tanggungan tersebut dimana Pemerintah menyediakan layanan termasuk Pendaftaran Hak Tanggungan yang terintegrasi secara elektronik. Tata cara layman HT yang diintegrasikan dengan elektronik dapat diketahui bahwa kreditur melakukan pengajuan permohonan layman HT elektronik lewat sisters yang tersedia dari pihak menteri. Pada perihal permohonan layanan tersebut berbentuk mendaftar hak tanggungan mau pun mengalihkannya disertai berkas-berkas yang melengkapi syarat -syarat yang telah tersampaikan dari PPAT.

Pada perihal permohonan layman tersebut berbentuk mendaftar hak tanggungan maupun mengalihkann ya disen ai berkas-berkas yang melengkapi syarat-syarat yang telah tersampaikan dari PPAT. Pada perihal permohonan layman ini juga berbentu k merubah nama kreditur, menghapus HT maupun memperbaiki data disertai berkas-berkas yang melengkapi syarat yang tersampaikan dari pihak kreditur. Syarat-syarat permohonan layman sistem ini disesuaikan terhadap aturan yang telah ditentukan dalam undang-undang serta tersampaikan berbentu k berkas secara elektronik.

Adapun mekanisme pendaftarann ya yang diterapkan pada PT. BPR Pedungan yang pertama yaitu pengguna yang telah berada pada daftar melakukan pengajuan permohonan pelayanan HT-el lewat sistemnya, di camping dokumen-dokumen syarat permohonan untuk mendaftar berbentu $\mathrm{k}$ doku men secara elektronik, pengguna turut diminta untuk membuatkan surat pemyataan tentang tanggung jawab secara absah mau pun benar mengenai data-data berkas elektronik yang telah dimasukkan. 
Untu k sertifikat yang dijadikan jaminan wajib diatasnamakan oleh debitur, permohonan terhadap pelayanan yang terdapat pada sistem dapat dijadikan tanda bukti mendaftar yang terbit dari sistem sedikitnya memiliki nomor berkas mendaftar dari pemohon, tanggal mendaftar, nama pengguna serta kode bayar terhadap pembiayaan pelayanan. Pelayanan sistem ini dikenai pembiayaan yang disesuaikan oleh aturan undang-undang tentang penerima an negara bukan pajak.

Sistem secara online memiliki beberapa kelemahan yakni kerawanan terjadi kesalahan pada pemasu kan data, mulai dari kesalahan masu knya sistem yang tertuju dan hal ini secara keseluruhan bergantung pada persiapan sumber daya pengelola yang dimiliki. (Setyawan, 2019) Adapun hambatan intemal pada PT. B PR Pedungan yaitu, kurang lengkapn ya data dari notaris yang men yebabkan status menjadi ditangguhkan, Surat perintah setor tidak boleh lewat dari 3 hari sejak tanggal pendaftaran yang kadang tidak dapat kita tepati sehingga harus didaftarkan ulang, raw an terjadi kesalahan pada proses memasukkan data mulai dari masukn ya menuju sistem yang diminta, lamanya mengecek sertifikat sebelum membuat akta untu k memberi HT, gangguan server seringkali muncul saat mengupload doku men.

Mekanisme pada Hak Tanggungan Konvensional, Bank memberi kuasa kepada PPAT dan menitipkan pembayaran biaya pendaftaran HT, PPAT membayarkan bea pendaftarann ya, mengambil Sertifikat dari Kantor Pert anahan, kemudian Bank menerima sertifikat yang sudah diberi catatan. Jadi dengan sistem konvensional hampir semuan ya dilakukan oleh PPAT. Dengan diber lakukannya layman serentak secara Nasional untuk Hak Tanggungan secara elektronik sejak 8 Juli 2020 berdasar Permen ATR/Kepala BPN Nomor S Tahun 2020, maka saat ini tidak ada lagi layanan dari BPN untuk Pemberian Hak Tanggungan secara konvensional. Pemberlakuan secara serentak layman Hak Tanggungan Elekt ronik tersebut tanpa melalui masa transisi dan sosialisasi yang memadai. Hal ini tentu memunculkan banyak persoalan terutama kendala/problematik yang dihadapi oleh para Pengguna Hak Tanggungan Elektronik.

Tidak bisa dilakukan pengembalian PN BP, jika jangka waktu koreksi (7 hari) sudah habis dan belum selesai maka PNBP menjadi hangus dan harus membayar ulang dengan proses mengulang dari awal. Prosedur pengembalian belu $\mathrm{m}$ ada pengaturannya. Aplikasi HTElektronik sering mengalami masalah yang terjadi pada saat jam kerja, sulit mengupload doku men atau pun mendaftar, sehingga perlu dilakukan berulang kali.Tidak adanya keterangan tentang identitas sertipikat hak atas tanah yang didaftar kan sebagaimana dalam sistem manual, dalam SPS hanya tertera kode billing. Status akta sudah terdaftar seharusnya saat setelah SPS dibayar bukan setelah Creditor upload Permohonan. Ketentuan Pasal 10 ayat (3) U U HT t idak dapat dilakukan dikarenakan hak tanggungan secara elektronik dengan basis data tanah yang telah memiliki sertifikat dan berada pada daftar Kantor Pertanahan, sementara pelayanan secara manual di seluruh Kantor Pertanahan sudah dihentikan sejak 8 Juli 2020. Dengan demikian terjadi adanya kekosongan Hukum untuk pelaksanaan Pasal 10 ayat (3) Undang-undang Hak Tanggungan.

\section{Efektivitas Pendaftaran Hak Tanggungan Secara Elektronik Pada PT. BPR Pedungan}

Keefektifan maupun tidak dari sebuah peraturan hukum terkait efektivitas pada hukum ditinjau dari optik sosiologi huku $\mathrm{m}$, hu kum adalah fenomena empiris, dan sifatnya hanya dapat dipahami dengan melihatnya dari perspektif masyarakat. Pengetahuan tentang bentuk hu $\mathrm{ku} \mathrm{m}$ diperlukan untuk menguji efektiv'itas hu kum. Dalam segala upaya agar dapat mencapai ha1-ha1 yang dituju dalam pembangunan yakni sistem hukum bisa berperan dengan mendukung. Ketidakefektifan dari sistem huku m pasti dapat memberi hambatan bagi pencapaian tujuan. Apabila tingkah laku individual pada kehidu pan bermasyarakat disesuaikan terhadap muatan yang menjadi ketentuan pada peraturan secara hukum yang diberlaku kan, maka sisters huku $\mathrm{m}$ tersebut dapat dikatakan efekt if.

Realitas huku m berkaitan dengan tingkah laku, apabila hukum dinyatakan legal berarti ditemu kan tingkah laku hu ku m, yaitu tingkah laku yang sesuai dengan cita-cita hukum. Oleh karena itu, jika didapati tingkah laku yang tidak disesuaikan terhadap hu kum secara idealisme yakni ketidaksesuaian terhadap ekspresi yang tersedia dalam UU maupun putusan hakim bisa diartikan jika perilaku tersebut ditemu kan pada saat idealisme hu kum yang berlaku namun tidak diberlakukan. Perihal ini turut mengetahui jika tingkah laku hukum tersebut dibentu k dikarenakan adanya pengaruh moti f maupun penggagasan, dengan demikian tentunya apabila didapati ketidak sesuaian tingkah laku terhadap huku $\mathrm{m}$ artinya terdapat pengaru $\mathrm{h}$ yang menghalangi mau pun terkendala dalam per 
wujudan tingkah laku yang disesuaikan berdasarkan hu kum yang berlaku.

Agar huku m dapat berlaku secara efektif tentunya kendala-kendala baik yang terjadi secara intemal mau pun ekstemal terkait dengan implementasi dari pendaftaran hak tanggungan mempergunakan sarana elektronik maka perlu dicarikan solusi untuk mengatasi kendala-kendala yang terjadi tersebut. Setelah melalui proses dari awal berlakunya yang sangat tingkat dan menemui berbagai kendala dalam melaksanakan pendaftaran secara elektronik, walaupun kadangkala menemui hambatan akan tetapi secara umu m sejak berlakunya pendaftaran secara elektronik kita rasakan efektif. Kita tidak perlu lagi mendatangi BPN untu k keperluan pendaftaran dan Roya jaminan yang telah lunas sena biaya yang lebih murah. Hambatan terus kita u payakan untuk diatasi agar semua berjalan lancar.

Terhadap prakteknya di lapangan memang masih mengalami berbagai macam kendala baik dari sisi sumber daya manusia nya mau pun juga dari ketersediaan jaringan yang memadai, atas kendala-kendala yang terjadi tersebut PT. B PR Pedungan tetap dapat menerapkan pendaftaran hak tanggungan yang secara elektronik dengan efektif sehingga dapat lebih cepat dan efisien dalam mengakses pelayanan hak tanggungan secara elektronik.

\section{SIMPULAN DAN SARAN}

\section{Simpulan}

Berdasarkan pembahasan yang telah diuraikan diatas maka dapatlah dit arik kesimpulan sebagai berikut

1. Mekanisme pelayanan hak tanggungan yang terintegrasi secara elektronik sebagaimana ditentukan dalam Pasal 9 Pemien ATR/KBPN Nomor 5 Tahun 2020 dapat diketahui bahwa permohonan layman tersebut berbentuk mendaftar hak tanggungan mau pun mengalihkann ya disertai berkasber kas yang melengkapi syarat-syarat yang telah tersampaikan dari PPAT. Pada perihal permohonan layman ini juga berbentuk meru bah nama kreditur, menghapus HT mau pun memperbaiki data disertai berkas-berkas yang melengkapi syarat yang tersampaikan dari pihak kreditur. Syarat-syarat permohonan layman sistem ini disesuaikan terhadap aturan yang telah ditentukan dalam undang-undang serta tersampaikan berbentu $\mathrm{k}$ ber kas secara elektronik.

2. Efektivitas penerapan Permen ATR/KBPN N o. 5 Tahun 2020 terhadap prakteknya di lapangan memang masih mengalami berbagai macam kendala baik dari sisi sumber daya manusia nya mau pun juga dari ketersediaan jaringan yang memadai, atas kendala-kendala yang terjadi tersebut PT. BPR Pedungan tetap dapat menerapkan aturan Permen No.5 Tahun 2020 mengenai pendaftaran hak tanggungan yang secara elektronik dengan efektif sehingga dapat lebih cepat dan efisien dalam mengakses pelayanan hak tanggungan secara elektronik.

\section{Saran}

Adapun saran yang dapat diberikan terkait dengan penelitian ini yait u sebagai berikut:

1. Hendaknya dalam pendaftaran hak tanggungan pihak bank selaku kreditor menyediakan sarana sumber daya manusia yang tidak gaptek untk menjadi administrator bank dalam mendaftarkan hak tanggungan secara elektronik.

2. Pihak bank juga diharapkan selalu menyediakan jaringan wifi yang baik agar tidak terdapat kendala saat mengu nggah data ht-el pada system. Selai $\mathrm{n}$ itu pihak bank selaku kreditur diharapkan untu $\mathrm{k}$ selalu memantau berkas yang sudah di unggah di system agar apabila terdapat perbaikan dari kantor pertanahan su paya segera bisa dilakukan perbaikan agar tidak lewat dari batas waktu yang telah ditentukan.

\section{DAFTAR PUSTAKA}

Anggara. (2010). Kontroversi UU ITE: Menggugat Pencemaran Nama Baik di Dunia Maya. PT.Penebar Swadaya. Jakarta.

Guntoro, J., Kontesa, E., \& Sauni, H. (2020). Tinjauan Yuridis Pendaftaran Hak Tanggungan Dalam Pelayanan Hak Tanggungan Terintegrasi Secara Elektronik. Bengkoelen Justice, Vol. 10(2).

Gunarta, I. M. D., Nurasa, A., \& Pinuji, S. (2020). Persepsi Kreditur Dan Ppat Terhadap Kualitas

Layanan HakTanggungan Terintegrasi Secara Elektronik. Jumal Tunas Agraria, Vol. 1(3).

Hardiyansyah. (2011). Kualitas pelayanan publik. Gava Media. Yogyakarta. 
Imanda, N. (2020). Lahimya Hak Tanggungan Menurut Peraturan Pemerintah Agraria Tentang Pelayanan Hak Tanggungan Terintegrasi Secara Elektronik. Jumal Hukum Kenotariatan, Vol.3(1).

M, Bahsan. (2007). Hukum Jaminan dan Jaminan Kredit Perbankan Indonesia. RajaGrafindo Persada. Jakarta.

Mulyono, E. L. (2003). Tinjauan Yuridis Undang-undang Nomor 4 tahun 1996 tentang Hak Tanggungan dalam Kaitannya dengan Pemberian Kredit oleh Perbankan. Harvarindo. Jakarta.

Nurwulan, P. (2021). Implementasi Pelayanan Hak Tanggungan Elektronik Bagi Kreditor Dan Pejabat Pembuat Akta Tanah. Lus Quia Lustum, Vol. 28(1).

Sinambela. (2011). Reformasi pelayanan publik. Bumi Aksara. Jakarta.

Usman, R. (2001). Aspek-Aspek Hukum Perbankan Di Indonesia. PT. Gramedia Pustaka Utama. Jakarta. 